\title{
Bilateral Internal Thoracic Artery Grafting in Women: A Word of Caution
}

\author{
Thibaut Schoell, MD, ${ }^{1}$ Laurent Genser, MD, PhD,${ }^{2}$ Marina Clément, MD,${ }^{1}$ Julien Amour, MD, PhD, ${ }^{3}$ \\ Pascal Leprince, $\mathrm{MD}, \mathrm{PhD},{ }^{1}$ Guillaume Lebreton, $\mathrm{MD},{ }^{1 *}$ Reza Tavakoli, $\mathrm{MD}, \mathrm{PhD}^{1 *}$ \\ Department of Cardiovascular Surgery, St. Mary's Hospital, Kurume, Japan Departments of ${ }^{1}$ Cardiovascular Surgery, Institut \\ de Cardiologie, ${ }^{2}$ Hepato-biliary and General Surgery, and ${ }^{3}$ Anesthesiology and Cardiac Surgical Intensive Care Unit, Institut de \\ Cardiologie, Groupe Hospitalier Pitié-Salpêtrière, Paris, France
}

\section{ABSTRACT}

Background: Despite the superior hemodynamic performance of internal thoracic arteries, total arterial revascularization with exclusive bilateral internal thoracic arteries (BITA) is less frequently used especially in specific subsets of patients, including females. We report our experience with total arterial revascularization with exclusive BITA regardless of sex and analyze the impact of female sex on the early and midterm outcomes.

Methods: Total arterial revascularization with exclusive BITA was performed with equal frequency in females (79/99, $80 \%)$ and males (392/477, $82 \% ; P=.68)$ undergoing isolated CABG for 3-vessel disease. Pre, intra and postoperative data were compared between these two groups.

Results: Complete revascularization was achieved in $77 \%$ of females and $72 \%$ of males $(P=.08)$. Early mortality did not differ between the groups $(6.3 \%$ versus $4.6 \%$, $P=.7)$. The incidence of re-sternotomy for bleeding, postoperative stroke, myocardial infarction, new onset atrial fibrillation, and hemofiltration for renal failure did not differ between the two groups. However, there were significantly more wound revision for combined superficial and deep sternal wound infection in females $(26.5 \%$ versus $5.1 \%, P=.0001)$. Nevertheless, midterm survival, freedom from repeat revascularization, myocardial infarction, stroke, and major adverse cardiovascular and cerebral events at five years were very good and compared favorably between females and males.

Conclusions: Our findings suggest that total arterial myocardial revascularization with exclusive internal thoracic arteries in females carries the same midterm benefits as in males. Early outcomes are comparable except for a higher incidence of wound revision for combined superficial and deep sternal wound infections in females compared to males. Benefits of bilateral internal thoracic artery grafting

Received fune 19, 2018; received in revised form November 15, 2018; accepted November 19, 2018.

*These authors contributed equally to this work.

Correspondence: Reza Tavakoli, Department of Cardiovascular Surgery, Institut de Cardiologie, Groupe Hospitalier Pitié-Salpêtrière, 52 Boulevard Vincent Auriol, 75013 Paris, France; +33-1-42-16-56-92; fax: +33-1-4216-56-84 (e-mail: reza.tavakoli@uzh.ch). in females should be weighed against increased risk of early wound revision.

\section{INTRODUCTION}

Left internal thoracic artery (LITA) to left anterior descending (LAD) bypass has been reported to improve survival and freedom from major adverse cardiac events at 10 years when compared to saphenous vein grafts (SVG) [Loop 1986]. These results have been further strengthened by the angiographic study of the LITA and SVG from the Coronary Artery Surgery Study (CASS), making the LITA the conduit of choice in coronary artery bypass grafting (CABG) surgery [Cameron 1996]. The improved long-term outcomes of patients undergoing LITA-LAD bypass has encouraged a number of centers to use the right internal thoracic artery (RITA) as the second conduit of choice in CABG surgery [Lytle 2004; Kurlansky 2010]. This strategy has been endorsed by an angiographic study demonstrating a long-term patency rate of the RITA to be equivalent to the LITA and superior to the radial artery and the SVGs [Tatoulis 2011].

However, for several reasons the use of bilateral internal thoracic arteries (BITA) for total arterial revascularization has not met the same acceptance as the LITA-LAD bypass: (I) extra time needed for preparation of BITAs plus increased risk of postoperative bleeding necessitating re-sternotomy; (II) technically more demanding BITA anastomoses; (III) concerns regarding increased adverse spastic responses of BITA to hemodynamic changes; (IV) possible atherosclerotic disease of the subclavian artery; (V) compromise of the blood flow to the sternum with subsequent higher rate of sternal wound infections. In fact, only $4 \%$ of the patients undergoing $\mathrm{CABG}$ in the United States have received BITA grafting [Tabata 2009; Itagaki 2013]. A few subsets of patients are commonly considered at higher risk of complications following BITA grafting and thus less likely to benefit from the use of a second internal thoracic artery conduit [Itagaki 2013]. Because of the perceived higher risk of postoperative complications, BITA grafting is significantly less frequently offered to female patients as compared to their male counterparts [Lytle 2004; Kurlansky 2010].

Here, we report our experience of total arterial revascularization with exclusive ITA grafting for three-vessel disease regardless of the sex of the patients and analyze the impact of female sex on early and midterm outcomes. 
Table 1. Female/Male Distribution for the Whole Patient Population Undergoing Isolated CABG and for Those with 3-Vessel Disease Revascularized Exclusively with BITA

\begin{tabular}{lccc}
\hline Isolated CABG & $(\mathrm{n}=890)$ & Female $(\mathrm{n}=185)$ & Male $(\mathrm{n}=705)$ \\
\hline Isolated CABG & Three-vessel disease $(\mathrm{n}=576)$ & $54 \%(99 / 185)$ & $69 \%(477 / 705)$ \\
Isolated CABG & Three-vessel disease, exclusive BITA $(\mathrm{n}=471)$ & $80 \%(79 / 99)$ & .00047 \\
$82 \%(392 / 477)$ & .68 &
\end{tabular}

\section{PATIENTS AND METHODS}

From January 2007 through December 2008, 890 patients underwent isolated CABG at our institution (Table 1). Of these, 576 patients $(65 \%)$ presented with three-vessel disease. In patients with three-vessel disease, 471 (82\%) were exclusively revascularized with internal thoracic arteries and constitute the study population of the present report. In our study, female sex was not considered a drawback for exclusive ITA grafting. This fact was reflected by the equal proportion of female $(79 / 99,80 \%)$ compared to male $(392 / 477,82 \%$, $P=.68)$ patients who underwent isolated CABG for threevessel disease with exclusive ITA grafting (Table 1). The study was approved by our Institutional Ethics Committee for retrospective data retrieval. Informed consent was obtained from every patient prior to the operation.

\section{Data Collection and Definition of Terms}

Hospital charts were reviewed for pre, intra, and postoperative data collection. Preoperatively (Table 2), emergency operation was defined as operation before the beginning of the next working day (EuroSCORE I) after decision to operate (EuroSCORE II). Peripheral vascular disease included all symptomatic and asymptomatic extracoronary arteriopathy. Cerebrovascular disease included past history of any cerebrovascular event with or without permanent neurological damage. A perioperative myocardial infarction was defined by the appearance of new Q waves in the ECG associated with elevated levels of creatine kinase-MB fraction (CK-MB). In our center, cardiac troponin (cTn) was not routinely measured during the study period. Therefore, the enzymatic definition was based on the measurements of CK-MB (>50 mU/ $\mathrm{mL}$ ) and the ratio of $\mathrm{CK}-\mathrm{MB} / \mathrm{CK}(>10 \%)$. A cerebrovascular accident was defined as a new permanent neurological deficit and computed tomographic evidence of cerebral infarction. Sternal wound infection included superficial as well as deep sternal infection that underwent wound revision with sternal rewiring.

\section{Surgery}

In all patients, access to the heart was gained through median sternotomy. Internal thoracic arteries were prepared by skeletonization. The LITA was preferentially routed to the LAD and the RITA mostly as Y-graft from the LITA to revascularize the circumflex and distal branches of the right coronary artery (Table 3). After heparinization, for on-pump operations cardiopulmonary bypass was established between the ascending aorta and the right atrium. Myocardial protection was achieved by multiple doses of antegrade warm blood cardioplegia.

\section{Follow-up}

Clinical follow-up was obtained by phone interview with the patients or their family, and/or with their general practitioner, and/or response to a patient questionnaire. The occurrence of postoperative major adverse cardiac and cerebrovascular events (MACCE) from hospital discharge to follow-up was recorded. MACCE was defined as the composite of death, myocardial infarction, cerebrovascular accident (CVA) or stroke, or repeat revascularization. Survival information was obtained from official death registries when direct contact sources were not available. If the patient had been hospitalized, inpatient records were obtained. For this study, follow-up was closed in September 2014.

\section{Statistical Analysis}

Continuous variables were expressed as median \pm SD with range (min-max) and compared between the two groups using non-parametric Mann-Whitney $U$ test. Categorical variables were expressed as numbers and percentages and compared between the two groups using Pearson chi-square test. Kaplan-Meier curves were compared using log-rank test. A two-sided $P$ value $<.05$ was considered to be significant. Statistical analysis and graphs were performed using GraphPad Prism version 6.01 (GraphPad, La Jolla, CA, USA).

\section{RESULTS}

\section{Preoperative Patient Characteristics}

Female patients were significantly older and had a higher incidence of arterial hypertension than male patients. There were significantly more current smokers among males than females. Other cardiovascular risk factors were present with the same frequency in both groups. The preoperative risk score judged by EuroSCORE I and II was significantly higher in females than in males. See Table 2.

\section{Intraoperative Data}

There were no differences regarding the configuration of BITA (Y-anastomosis or in situ) grafting between the two groups. The mean number of distal anastomoses and the completeness of revascularization was comparable in females and males. However, the cross-clamp time was slightly but significantly higher in males as compared to females. See Table 3.

\section{Early Outcomes}

Early mortality was comparable between female and male patients $(6.3 \%$ versus $4.6 \%, P=.71)$. The incidence of stroke, 
Table 2. Preoperative Patient Characteristics

\begin{tabular}{|c|c|c|c|}
\hline & Female $(n=79)$ & Male $(n=392)$ & $P$ \\
\hline Age, y & $71.2 \pm 8(64-78)$ & $65 \pm 8(57-73)$ & $<.0001$ \\
\hline Body mass index, $\mathrm{kg} / \mathrm{m}^{2}$ & $26.9 \pm 4(23-30)$ & $26.3 \pm 3(24-29)$ & 0.97 \\
\hline Dyslipidemia, n (\%) & $59(75)$ & $308(79)$ & .54 \\
\hline Arterial hypertension, $\mathrm{n}(\%)$ & $63(80)$ & $255(65)$ & .016 \\
\hline Current smoker, n (\%) & $7(9)$ & $81(21)$ & .02 \\
\hline Diabetes on insulin, $\mathrm{n}(\%)$ & $14(18)$ & $53(14)$ & .43 \\
\hline $\begin{array}{l}\text { Diabetes on oral medica- } \\
\text { tion, } \mathrm{n}(\%)\end{array}$ & $22(28)$ & $97(25)$ & .66 \\
\hline $\begin{array}{l}\text { Chronic obstructive pulmo- } \\
\text { nary disease, } \mathrm{n}(\%)\end{array}$ & $9(11)$ & $44(11)$ & 1 \\
\hline $\begin{array}{l}\text { Preoperative creatinine } \\
>200 \mu \mathrm{mol} / \mathrm{L}, \%\end{array}$ & $6(8)$ & $40(10)$ & .61 \\
\hline Dialysis-dependent, n (\%) & $2(3)$ & $5(1)$ & .74 \\
\hline $\begin{array}{l}\text { Previous thoracic irradia- } \\
\text { tion, } \mathrm{n}(\%)\end{array}$ & $1(1)$ & $0(0)$ & .37 \\
\hline $\begin{array}{l}\text { Cerebrovascular disease } \\
\text { (history of stroke), n (\%) }\end{array}$ & $10(13)$ & $23(6)$ & .055 \\
\hline $\begin{array}{l}\text { Peripheral arterial disease, } \\
\text { n (\%) }\end{array}$ & $11(14)$ & $75(19)$ & .35 \\
\hline Redo surgery, n (\%) & $1(1)$ & $1(0)$ & 1 \\
\hline EuroSCORE I & $6 \pm 2(5-8)$ & $4 \pm 2(3-6)$ & $<.001$ \\
\hline EuroSCORE II & $1.96 \pm 2(1-3)$ & $2.1 \pm 2(1-2)$ & $<.001$ \\
\hline $\begin{array}{l}\text { Acute coronary syndrome, } \\
n(\%)\end{array}$ & $39(50)$ & $185(47)$ & .82 \\
\hline Unstable angina, $\mathrm{n}(\%)$ & $10(13)$ & $47(12)$ & 1 \\
\hline $\begin{array}{l}\text { Myocardial infarction <3 } \\
\text { months, } \mathrm{n}(\%)\end{array}$ & $25(32)$ & $103(26)$ & .40 \\
\hline $\begin{array}{l}\text { Acute pulmonary edema, } \\
\mathrm{n}(\%)\end{array}$ & $10(13)$ & $26(7)$ & .11 \\
\hline Cardiogenic shock, n (\%) & $2(3)$ & $7(2)$ & 1 \\
\hline Left main disease, $\mathrm{n}(\%)$ & $21(27)$ & $132(34)$ & .27 \\
\hline Ejection fraction, \% & $54.7 \pm 9$ & $52.1 \pm 10$ & .11 \\
\hline$<.35, \mathrm{n}(\%)$ & $7(9)$ & $29(7)$ & .83 \\
\hline Previous angioplasty, n (\%) & $10(13)$ & $68(17)$ & .39 \\
\hline Emergency, n (\%) & $14(18)$ & $69(18)$ & 1 \\
\hline
\end{tabular}

myocardial infarction, new onset atrial fibrillation, re-sternotomy for bleeding, and hemofiltration for acute renal failure did not differ between the groups. Importantly, the incidence of wound revision for combined superficial and deep sternal wound infections was higher in females as compared to males. See Table 4.

\section{Midterm Outcomes}

Midterm survival at 5 years was similar for females and males (82.6\% versus $83.6 \%$ respectively; $P=.80$ ) (Figure 1 ).

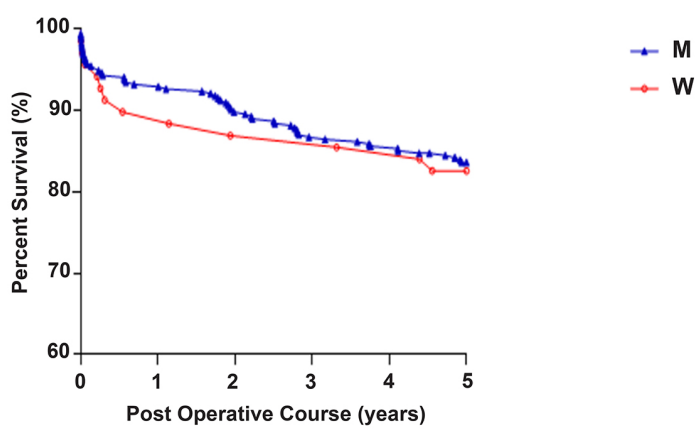

Figure 1. Kaplan-Meier survival curves for females (W) and males (M).

There was no significant difference between the 2 groups at 5 years.

At 5 years, in female patients, freedom from repeat revascularization, myocardial infarction, stroke, and MACCE were comparable to male patients $(89.7 \%$ versus $95.3 \%, P=.10$; $98.3 \%$ versus $96.3 \%, P=.43 ; 98.3 \%$ versus $90.9 \%, P=.53$; $73.9 \%$ versus $76.2 \%, P=.71$, respectively) (Figure 2 ).

\section{DISCUSSION}

The use of the left internal thoracic artery to bypass the left anterior descending artery has been shown to provide superior long-term survival and outcomes compared to saphenous vein grafts [Loop 1986; Cameron 1996]. In the 2011 American College of Cardiology/American Heart Association guidelines, LIMA-LAD bypass is a class I recommendation [Hillis 2012]. Accumulating evidence suggests that the use of both internal arteries is accompanied by additional improvement in long-term survival and outcomes when compared to single ITA grafting [Itagaki 2013; Takagi 2014]. In the 2011 American College of Cardiology/American Heart Association
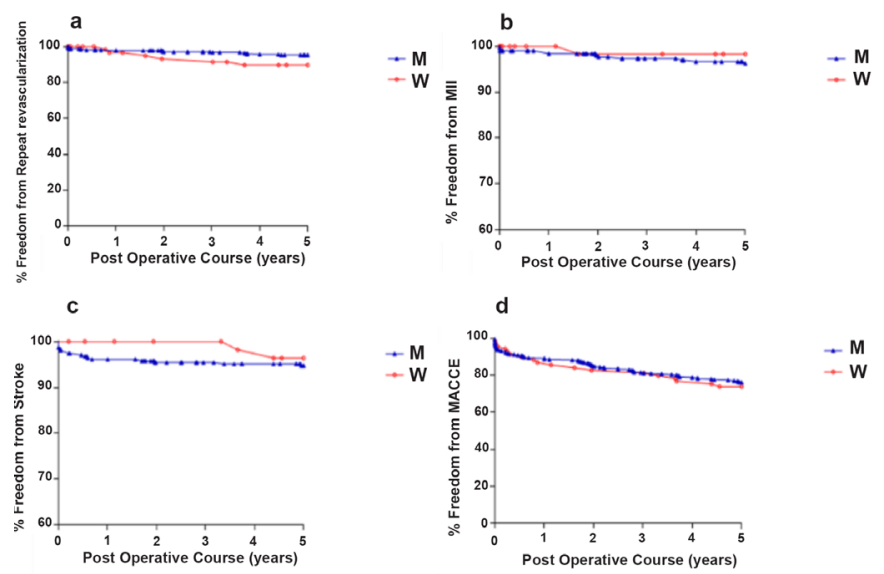

Figure 2. Kaplan-Meier curves of freedom from a) repeat revascularization, b) myocardial infarction (MI), c) stroke, and d) major adverse cardiovascular and cerebral events (MACCE). At 5-year midterm, females (W) benefited to the same degree from bilateral internal thoracic artery grafting as their male (M) counterparts. 
Table 3. Intraoperative Data

\begin{tabular}{lccc}
\hline & Female $(\mathrm{n}=79)$ & Male $(\mathrm{n}=392)$ & $P$ \\
\hline $\begin{array}{l}\text { BITA use with Y-anastomosis, } \\
\mathrm{n}(\%)\end{array}$ & $60(76)$ & $283(72)$ & .59 \\
$\begin{array}{l}\text { BITA use with in situ, } \mathrm{n}(\%) \\
\text { Number of distal anastomoses }\end{array}$ & $19(24)$ & $109(28)$ & \\
$\begin{array}{l}\text { Complete revascularization, } \\
\mathrm{n}(\%)\end{array}$ & $61(77)$ & $281(72)$ & .076 \\
$\begin{array}{l}\text { Cross-clamp time, min } \\
\text { Off-pump, } \mathrm{n}(\%)\end{array}$ & $54 \pm 13(47-69)$ & $61 \pm 14(51-73)$ & .018 \\
& $1(1)$ & $2(1)$ & 1
\end{tabular}

guidelines, use of a second internal thoracic artery to bypass the circumflex or right coronary artery is a class IIa recommendation [Hillis 2012]. Despite these recommendations, BITA grafting is largely underused [Tabata 2009; Itagaki 2013], particularly in females [Lytle 2004; Kurlansky 2010]. Females have been reported to present with higher morbidity [Nicolini 2016; Raza 2014] and mortality [Bukkapatnam 2010; Gansera 2004] than males after isolated CABG. Female sex has been associated with increased rate of hospital readmission for myocardial infarction and congestive heart failure [Nicolini 2016]. Female sex associated with higher body mass index and diabetes were reported to be risk factors for sternal wound infection after isolated CABG using BITA grafting [Loop 1986]. These studies have supported the common preference to avoid total arterial revascularization and use of both internal thoracic arteries in female patients [Gansera 2004; Ennker 2009]. Since 2000 we have been offering total arterial revascularization with exclusive internal thoracic arteries to the majority of patients with multi-vessel coronary artery disease regardless of their sex. In the present retrospective study in a cohort of patients with coronary artery three-vessel disease undergoing isolated CABG with exclusive internal thoracic arteries, we examined the impact of female sex on early and midterm outcomes. In our series, the early mortality, defined as in-hospital death, was $6.3 \%$ in females and comparable to that of males $(4.6 \%, P=.71)$. Reported early mortality in females undergoing BITA grafting reaches $4 \%$ [Gatti 2017] and 4.1\% [Gansera 2004]. In a large retrospective study, early mortality in females after isolated CABG was $4.6 \%$ [Bukkapatnam 2010]. In this study, among early postoperative complications, only the incidence of wound revision for combined superficial and deep sternal wound infections was significantly higher in females $(26.5 \%)$ than in males $(5.1 \%$, $P<.000)$. It should be noted that we have adopted an aggressive approach to superficial sternal wound infection similar to deep sternal wound infection with re-sternotomy, debridement and re-wiring. This strategy has permitted us to reduce the mortality of combined superficial and deep sternal wound infections to $10 \%$ (4 of 41) without adverse impact on overall early mortality. The mortality associated with reoperation for sternal wound infection in our series is inferior to the study of Dubert et al reporting $12 \%$ death rate following reoperation for sternal wound infection [Dubert 2015]. Following BITA
Table 4. Early Outcomes

\begin{tabular}{|c|c|c|c|}
\hline & $\begin{array}{l}\text { Female } \\
(n=79)\end{array}$ & $\begin{array}{c}\text { Male } \\
(\mathrm{n}=392)\end{array}$ & $P$ \\
\hline In-hospital death, n (\%) & $5(6.3)$ & $18(4.6)$ & .71 \\
\hline Stroke, n (\%) & 0 & $5(1)$ & .68 \\
\hline $\begin{array}{l}\text { Perioperative myocardial } \\
\text { infarction, } \mathrm{n}(\%)\end{array}$ & 0 & $5(1)$ & .68 \\
\hline Atrial fibrillation, $\mathrm{n}(\%)$ & $12(15)$ & $35(9)$ & .14 \\
\hline Re-sternotomy for bleeding, n (\%) & $2(2.5)$ & $7(1.8)$ & 1 \\
\hline $\begin{array}{l}\text { Re-sternotomy for sternal } \\
\text { wound infection, } \mathrm{n}(\%)\end{array}$ & $21(26.5)$ & $20(5.1)$ & .00000000025 \\
\hline $\begin{array}{l}\text { Hemofiltration for acute renal } \\
\text { failure, } n(\%)\end{array}$ & $5(6.3)$ & $7(2)$ & .052 \\
\hline
\end{tabular}

grafting in females, Gatti et al reported a $14.7 \%$ rate of sternal wound infections [Gatti 2017] and Gansera et al a combined rate of $5.7 \%$ of re-sternotomy for deep sternal wound infection and sternal re-fixation [Gansera 2004]. In a recent study, Lemaignen and co-workers found in multivariate analysis the interaction of female sex and CABG with two ITAs significantly associated with sternal wound infections [Lemaignen 2015]. The high incidence of wound revision for combined superficial and deep sternal wound infection in females in our study was not associated with higher body mass and diabetes reported by other groups [Ennker 2009], as these parameters were comparable between female and male cohorts. Inadequate perioperative management of glycemic values has been associated with higher post-operative morbidity including the incidence of sternal wound infections [Tennyson 2013]. However, in this study the perioperative glycemic management followed the same protocol in our female and male patients. This finding supports the observation of Raza and co-workers reporting female sex per se as a risk factor for sternal wound infection following BITA grafting for CABG [Raza 2014]. The EuroSCORE I and II were significantly higher in females as compared to males in our study, mainly because of the older age of the former group. Moreover, the female sex increases the EuroSCORE I by one point. The higher EuroSCORE in our female patients compared to male patients might have contributed to the worse incidence of sternal wound revisions. The incidence of the other early postoperative complications was comparable between females and males in our study. Moreover, the rates of early postoperative stroke (0\%), myocardial infarction $(0 \%)$, hemofiltration (1\%) and reexploration for bleeding $(3.8 \%)$ in our female patients compare favorably with those reported by Gatti et al [Gatti 2017] (1.7\%, 2.5\%, $1.5 \%$, and $1.7 \%$ respectively) and Gansera et al [Gansera 2004] (not available, $5.1 \%$, not available, and $1.5 \%$ respectively).

Midterm outcomes at 5 years were similar between female and male patients in our series and compare favorably with those after CABG from 2 large prospective randomized controlled trials, SYNTAX and Freedom [Mohr 2013; Farkouh 
2012]. The 5-year survival, freedom from repeat revascularization, myocardial infarction, stroke and MACCE in our female patients were $82.6 \%, 89.7 \%, 98.3 \%, 98.3 \%$ and $76.2 \%$ compared to those from the SYNTAX study $(88.6 \%$, $86.3 \%, 96.2,96.3 \%$, and $73.1 \%$ respectively) [Mohr 2013] as well as to the Freedom study $(89.1 \%$, not available, $96.1 \%$, $96.2 \%$, and $81.3 \%$ respectively) [Farkouh 2012].

The limitations of this study reside in the retrospective nature of the analysis. Besides, control coronary angiography was performed only in a small number of patients who presented with signs of myocardial ischemia. Therefore, there was no imaging information on patency of BITA grafts. The high incidence of wound revision for combined superficial and deep sternal wound infections in females might have been due to increased mechanical shear stress of voluminous breasts and reduced sternal vascularization. These characteristics are not collected in our database so verifying these hypotheses warrants future investigations.

In conclusion, despite the limitations of this study our findings suggest that total arterial myocardial revascularization with exclusive internal thoracic arteries in females carries the same midterm benefits as in males. Early outcomes are comparable except for a higher incidence of wound revision for combined superficial and deep sternal wound infections. Benefits of bilateral internal thoracic artery grafting in females should be weighed against increased risk of early wound revision.

\section{REFERENCES}

Bukkapatnam RN, Yeo KK, Li Z, et al. 2010. Operative mortality in women and men undergoing coronary artery bypass grafting (from the California Coronary Artery Bypass Grafting Outcomes Reporting Program). Am J Cardiol 105:339-42.

Cameron A, Davis KB, Green, G, et al. 1996. Coronary bypass surgery with internal-thoracic-artery grafts-effects on survival over a 15-year period. N Engl J Med 334:216-20.

Dubert M, Pourbaix A, Alkhoder S, et al. 2015. Sternal wound Infection after cardiac surgery: Management and outcome. PLoS ONE 10:e0139122.

Ennker IC, Albert A, Pietrowski D, et al. 2009. Impact of gender on outcome after coronary artery bypass surgery. Asian Cardiovasc Thorac Ann 17:253-8.

Farkouh ME, Domanski M, Sleeper LA, et al. 2012. Strategies for multivessel revascularization in patients with diabetes. N Engl J Med 367:2375-84.

Gansera B, Gillrath G, Lieber M, et al. 2004. Are men treated better than women? Outcome of male versus female patients after CABG using bilateral internal thoracic arteries. Thorac Cardiovasc Surg 52:261-7.

Gatti G, Maschietto L, Morosin M, et al. 2017. Routine use of bilateral internal thoracic artery grafting in women: A risk factor analysis for poor outcomes. Cardiovasc Revasc Med 18:40-6.

Hillis LD, Smith PK, Anderson JL, et al. 2012. 2011 ACCF/AHA guideline for coronary artery bypass graft surgery: executive summary: a report of the American College of Cardiology Foundation/American Heart Association Task Force on Practice Guidelines. J Thorac Cardiovasc Surg 143:4-34. Erratum in: J Thorac Cardiovasc Surg 2012;143:1235.

Itagaki S, Cavallaro P, Adams DH, et al. 2013. Bilateral internal mammary artery grafts, mortality and morbidity: an analysis of 1526360 coronary bypass operations. Heart 99:849-53.

Kurlansky PA, Traad EA, Dorman MJ, et al. 2010. Thirty-year follow-up defines survival benefit for second internal mammary artery in propensity-matched groups. Ann Thorac Surg 90:101-8.

Lemaignen A, Birgand G, Ghodhbane W, et al. 2015. Sternal wound infection after cardiac surgery: incidence and risk factors according to clinical presentation. Clin Microbiol Infect 21:674.

Loop FD, Lytle BW, Cosgrove DM, et al. 1986. Influence of the internal-mammary-artery graft on 10-year survival and other cardiac events. N Engl J Med 314:1-6.

Lytle BW, Blackstone EH, Sabik JF, et al. 2004. The effect of bilateral internal thoracic artery grafting on survival during 20 postoperative years. Ann Thorac Surg 78:2005-14.

Mohr FW, Morice MC, Kappetein AP, et al. 2013. Coronary artery bypass graft surgery versus percutaneous coronary intervention in patients with three-vessel disease and left main coronary disease: 5-year follow-up of the randomized, clinical SYNTAX trial. Lancet 381:629-38.

Nicolini F, Vezzani A, Fortuna D, et al. 2016. Gender differences in outcomes following isolated coronary artery bypass grafting: long-term results. J Cardiothoracic Surg 11:144.

Raza S, Sabik JF 3rd, Masabni Ket al. 2014. Surgical revascularization techniques that minimize surgical risk and maximize late survival after coronary artery bypass grafting in patients with diabetes mellitus. J Thorac Cardiovasc Surg 148:1257-64.

Tabata M, Grab JD, Khalpey Z, et al. 2009. Prevalence and variability of internal mammary artery graft use in contemporary multivessel coronary artery bypass graft surgery: analysis of the Society of Thoracic Surgeons National Cardiac Database. Circulation 120:935-40.

Takagi H, Goto SN, Watanabe T, et al. 2014. A meta-analysis of adjusted hazard ratios from 20 observational studies of bilateral versus single internal thoracic artery coronary artery bypass grafting. J Thorac Cardiovasc Surg 148:1282-90.

Tatoulis J, Buxton BF, Fuller JA. 2011. The right internal thoracic artery: the forgotten conduit - 5,766 patients and 911 angiograms. Ann Thorac Surg 92:9-17.

Tennyson C, Lee R, Attia R. 2013. Is there a role for HbA1c in predicting mortality and morbidity outcomes after coronary artery bypass graft surgery? Interact Cardiovasc Thorac Surg 17:1000-8. 